\title{
Dyslipidemia Management after Pre-eclampsia: What is the Threshold for Treatment Due to Increased Cardiovascular Risk?
}

\author{
Sheila J Rodger MD, Winnie Sia MD
}

DOI: 10.22374 /cjgim.v13i3.199

\begin{abstract}
About the Authors
Sheila Rodger is with the Department of Medicine, University of Calgary, Calgary, Alberta, Canada. Winnie Sia is with the Department of Medicine and Obstetrics and Gynecology, University of Alberta, Edmonton, Alberta, Canada. Corresponding author:Winnie Sia Winnie.Sia@albertahealthservices.ca

Submitted: April 10, 2017; Accepted: June 10, 2018. Published: August 27, 2018.
\end{abstract}

\begin{abstract}
Growing evidence shows that women with a history of pre-eclampsia, pregnancy-induced hypertension or gestational diabetes are at increased long-term risk of cardiovascular disease (CVD). This was incorporated in the American Heart Association's 2011 guideline on the prevention of CVD in women and was recently reflected in the 2016 Canadian Cardiovascular Society's guidelines, suggesting that young women who would not formerly have been considered for primary CVD prevention may benefit from screening for dyslipidemia. However, the indications and targets for medical treatment of dyslipidemia postpartum remain unclear and in fact differ amongst guidelines. We present the case of a 31-year-old G1P1L2 woman with pre-eclampsia, preterm delivery and dyslipidemia who had active vascular risk reduction postpartum, including adjustment of antihypertensives, diet and exercise counselling for lowdensity lipoprotein cholesterol reduction and weight loss promotion, and consideration of an HMG-CoA reductase inhibitor, which was ultimately decided against given the improvements seen with lifestyle modifications.
\end{abstract}

\section{RESUME}

Des preuves de plus en plus nombreuses montrent que les femmes ayant des antécédents de pré-éclampsie, d'hypertension induite par la grossesse ou de diabète gestationnel sont exposées à un risque accru de maladie cardiovasculaire (MCV) à long terme. Elle a été incorporée dans les lignes directrices de 2011 de l'American Heart Association sur la prévention des maladies cardiovasculaires chez les femmes et a récemment été reflétée dans les lignes directrices de 2016 de la Société canadienne de cardiologie, suggérant que les jeunes femmes qui n’auraient jamais été considérées comme prévention primaire des MCV pourraient bénéficier du dépistage de la dyslipidémie. Cependant, les indications et les cibles pour le traitement médical de la dyslipidémie post-partum restent peu claires et en fait diffèrent des lignes directrices. Nous présentons le cas d'une femme G1P1L2 âgée de 31 ans avec pré-éclampsie, accouchement prématuré et dyslipidémie ayant une réduction active du risque vasculaire post-partum, y compris l'ajustement des antihypertenseurs, un régime alimentaire et des exercices pour la réduction du cholestérol à lipoprotéines de basse densité et la prise en compte d'un inhibiteur de la HMG-CoA réductase, qui a finalement été rejeté compte tenu des améliorations observées avec les modifications du mode de vie. 


\section{Case}

Our non-smoking 31-year-old G1P1L2 female patient had a pre-pregnancy body mass index (BMI) of 40.1, dyslipidemia, and a family history of dyslipidemia and pre-eclampsia. Two years prior to pregnancy, her total cholesterol was $6.06 \mathrm{mmol} / \mathrm{L}$, low-density lipoprotein cholesterol (LDL-C) $4.81 \mathrm{mmol} / \mathrm{L}$ and ratio of total cholesterol to high-density lipoprotein cholesterol (HDL-C) 6.6. After treatment with a low-dose HMG-CoA reductase inhibitor (statin), her LDL dropped to 2.06. Prenatal labwork was otherwise normal, and an oral glucose tolerance test was negative for gestational diabetes. When she became pregnant, she was taking omega-3 fatty acids, but had stopped her statin for pregnancy.

At 30 weeks into her diamniotic, dichorionic twin pregnancy, she developed pre-eclampsia, with hypertension, proteinuria, headache, vision changes, thrombocytopenia and elevated transaminases. Her twins were delivered 5 days later by Caesarean section for pre-eclampsia and breech/breech presentation. Her symptoms resolved and laboratory markers normalized soon after delivery; however, she still required medications for blood pressure control.

She was referred to the Postpartum Pre-eclampsia Clinic (PPPC), a Specialty Vascular Risk Reduction clinic run by a general internist dedicated to women who have developed pre-eclampsia, ${ }^{1-3}$ for education and active management advice regarding the patient's long-term risk of vascular disease following preterm pre-eclampsia and her future risk of pre-eclampsia in subsequent pregnancies. ${ }^{4}$ At her initial visit 3 months postpartum she was assessed by the multidisciplinary team consisting of a physician, nurse practitioner, pharmacist and dietitian; her BMI at that time was 40 . An action plan was developed which included limiting saturated fat intake and beginning a program of exercise 3 times per week.

At the 7 months postpartum follow-up visit, our patient was exercising aerobically 3 to 5 times weekly and her BMI had decreased to 39.3; her antihypertensive medications were weaned and discontinued by 4 months post-partum. Her fasting lipids after stopping lactation were: triglycerides (TG) $1.27 \mathrm{mmol} / \mathrm{L}$ (normal $<1.70 \mathrm{mmol} / \mathrm{L})$, total cholesterol $5.03 \mathrm{mmol} / \mathrm{L}(<6.20 \mathrm{mmol} / \mathrm{L})$, HDL-C $0.75 \mathrm{mmol} / \mathrm{L}(>1.10 \mathrm{mmol} / \mathrm{L})$ and LDL-C $3.7 \mathrm{mmol} / \mathrm{L}$. Her LDL-C would be considered acceptable according to the current Canadian Cardiovascular Society (CCS) guidelines ${ }^{2}$ (see Table 1); however, given her history of pre-eclampsia, the American Heart Association's (AHA) 2011 Guidelines for the Prevention of Cardiovascular Disease (CVD) in Women and the Pre-eclampsia Foundation recommend a lower target of LDL-C $<2.6 \mathrm{mmol} / \mathrm{L} .{ }^{1,5}$ The clinic dietician therefore provided dietary recommendations for LDL-C reduction, including increasing fiber and whole grains and reducing prepackaged food intake.
From 7 to 12 months postpartum, our patient's weight had decreased by $1.1 \mathrm{~kg}$ and her BMI was 38.5. Unfortunately, her total cholesterol increased to $5.62 \mathrm{mmol} / \mathrm{L}$ and LDL-C increased to $4.3 \mathrm{mmol} / \mathrm{L}$. Hence, not only was it unclear whether or not she met criteria for "dyslipidemia" as the CCS and AHA/Preeclampsia guidelines differ in this population, it was even less clear if this possible dyslipidemia should be treated aggressively, such as with pharmacological therapy.

The PPPC team decided to further investigate her possible dyslipidemia with bloodwork. Her lipoprotein(a) was slightly elevated at $0.43 \mathrm{~g} / \mathrm{L}(<0.30 \mathrm{~g} / \mathrm{L})$; as per the CCS 2016 guidelines, this indicates an increased risk for CVD. ${ }^{2}$ Apolipoprotein B100 (Apo B) was also slightly elevated at $1.21 \mathrm{~g} / \mathrm{L}(<1.20 \mathrm{~g} / \mathrm{L})$, but her LDL-C had decreased to $3.73 \mathrm{mmol} / \mathrm{L}$. Given both the improvement in LDL-C with lifestyle modifications and the finding that her lipoprotein(a) and Apo B levels were not significantly elevated, no pharmacological treatment was recommended by the clinic. At this time, her 10-year risk of CVD as per the American College of Cardiology (ACC)/AHA risk calculator was $1.7 \%$ or "low risk", although the clinic was fully aware that the Fragminham 10-year risk prediction in such a young woman in this population is not valid. She was discharged from the PPPC back to her family physician with the recommendation to check her lipid panel every 1-2 years, although the optimal frequency of screening in this population is also not well-defined in any guidelines. The clinic suggested for the family physician to aim for an LDL of low 3 or high 2 range, until future guidelines can clarify the threshold.

\section{Discussion}

To our knowledge, this is the first published case of a woman with pre-eclampsia and preterm delivery who had active vascular risk reduction postpartum, despite the fact that women with a history of pre-eclampsia have been shown to be at increased risk of CVD. ${ }^{6-9}$ It brings to light the clinical challenges regarding: (1) the establishment of an appropriate LDL-C target in this population, and (2) the aggressiveness of dyslipidemia management. There has been emerging literature on the association between the history of pre-eclampsia and long-term vascular risk: a prospective longitudinal cohort study and two systemic reviews with metaanalyses have shown that women with pre-eclampsia have a higher long-term risk of CVD (2 to 5.6 times), hypertension (3.7 times) and stroke (1.8 times). ${ }^{6-8}$ In addition, these women are at risk for premature CVD: a population-based study showed that the mean age of a first cardiovascular event was 38.3 years in women with a history of maternal placental syndromes. ${ }^{9}$ While there is some evidence that lifestyle interventions help to reduce cardiovascular risk in women with a history of preeclampsia, ${ }^{7}$ the thresholds for starting what will likely be lifelong 
Table 1. LDL-C Target for Women with History of Hypertensive Disorders of Pregnancy and Pre-eclampsia

\begin{tabular}{|c|c|}
\hline Guidelines & LDL-C Target or Indication for Therapy in mmol/L (mg/dL) \\
\hline AHA $2011^{1}$ & $\begin{array}{l}\text { - Target LDL-C }<2.6(<100) \text { in women with history of pre-eclampsia, gestational diabetes, or pregnancy- } \\
\text { induced hypertension }\end{array}$ \\
\hline Pre-eclampsia Foundation ${ }^{5}$ & - Target LDL-C <2.6 (<100) \\
\hline AHA/ACC $2013^{10}$ & $\begin{array}{l}\text { - After ruling out secondary causes of hyperlipidemia, treat if age } \geq 21 \text { and LDL-C } \geq 4.91 \text { ( } \geq 190) \text {, with goal } \\
\text { of } \geq 50 \% \text { reduction } \\
\text { - Consider treating if } L D L-C \geq 4.14 \text { ( } \geq 160) \text {; no specific reference to pre-eclampsia }\end{array}$ \\
\hline $\operatorname{CCS} 2016^{2}$ & $\begin{array}{l}\text { - In "intermediate" risk group, treat if } L D L-C \geq 3.5(\geq 135) \text { with target of }>50 \% \text { LDL-C reduction or LDL-C } \\
<2.0(<77) \\
\text { - In "low" risk group, treat if LDL-C } \geq 5.0(\geq 193) \text { with goal of } 50 \% \text { reduction }\end{array}$ \\
\hline
\end{tabular}

AHA = American Heart Association; ACC = American College of Cardiology; CCS = Canadian Cardiovascular Society; LDL-C = Low-density lipoprotein cholesterol; HDL-C = High-density lipoprotein cholesterol; $\mathrm{TC}=$ Total cholesterol.

medication and the potential targets of medical management have not been clear.

The 2011 AHA Guidelines for the Prevention of CVD in Women ${ }^{1}$ reflects the above evidence by including pre-eclampsia, pregnancy-induced hypertension and gestational diabetes mellitus as factors that put women in the "at risk" category for CVD, along with smoking, hypertension, dyslipidemia, obesity, poor diet, physical inactivity, family history, metabolic syndrome, advanced subclinical atherosclerosis, and systemic autoimmune collagen-vascular diseases such as lupus or rheumatoid arthritis. Both these guidelines and the Pre-eclampsia Foundation suggest a target $\mathrm{LDL}$ of $<2.6 \mathrm{mmol} / \mathrm{L}^{5}$ (based on expert opinions as currently there is no data on this issue) through lifestyle changes as well as medication if required.

The 2016 Canadian guidelines have now included hypertensive diseases of pregnancy as an indication to screen for dyslipidemia. ${ }^{2}$ The pharmacological treatment indications for primary prevention include: (1) high Framingham Risk Score (FRS) $\geq 20 \%$, regardless of LDL-C level, and (2) intermediate FRS (10-19\%) with LDL-C $\geq 3.5 \mathrm{mmol} / \mathrm{L}$, non-HDL-C $\geq 4.3 \mathrm{mmol} / \mathrm{L}$, Apo B $\geq 1.2 \mathrm{~g} / \mathrm{L}$, or men $\geq 50$ and women $\geq 60$ years old with 1 additional CVD risk factor. Conditions for which a statin is indicated as initial therapy include: clinical atherosclerosis, abdominal aortic aneurysm, diabetes mellitus (age $\geq 40$ years, 15 -year duration for age $\geq 30$ (DM 1) or microvascular disease), chronic kidney disease (age $\geq 50$ years with estimated glomerular filtration rate $<60 \mathrm{~mL} /$ $\mathrm{min} / 1.73 \mathrm{~m}^{2}$ or albumin-to-creatinine ratio $>3 \mathrm{mg} / \mathrm{mmol}$ ), or LDL-C $\geq 5.0 \mathrm{mmol} / \mathrm{L}$. With the exception of LDL-C $\geq 5.0$ $\mathrm{mmol} / \mathrm{L}$, the treatment targets for all of the above are LDL-C $<2.0 \mathrm{mmol} / \mathrm{L}$ or $>50 \%$ decrease, ApoB $<0.8 \mathrm{~g} / \mathrm{L}$, or non-HDL-C
$<2.6 \mathrm{mmmol} / \mathrm{L}$. The target for LDL-C $\geq 5.0 \mathrm{mmol} . \mathrm{L}$ is $>50 \%$ decrease in LDL-C. Of note, our patient would not have met any of these CCS 2016 criteria for pharmacological treatment.

In comparison, the 2013 ACC/AHA Guideline on the Treatment of Blood Cholesterol to Reduce Atherosclerotic Cardiovascular Risk in Adults, ${ }^{10}$ which does not specifically address pre-eclampsia, recommends primary prevention with a high intensity statin for adults aged 21 and older with LDL-C $\geq 4.91 \mathrm{mmol} / \mathrm{L}$, with the goal of at least a $50 \%$ reduction in LDL-C. For individuals $<40$ years of age with LDL-C $<4.91 \mathrm{mmol} / \mathrm{L}$, these guidelines state that statin therapy for primary prevention may be considered in select individuals with risk factors such as LDL-C $\geq 4.14 \mathrm{mmol} / \mathrm{L}$, which would include patients such as ours. As such, the current guidelines differ on the threshold of lipids for treatment in young women who had a history of preeclampsia, or hypertensive disorder of pregnancy. This makes it very challenging for General Internists to actively reduce the vascular risks in these young women who have an increased long-term risk.

\section{Conclusion}

This case of a postpartum woman with dyslipidemia and a history of pre-eclampsia illustrates the challenges involved in determining the optimal management for cardiovascular risk reduction in the context of increasing evidence that pregnancy complications such as pre-eclampsia, pregnancy-induced hypertension and gestational diabetes lead to an increased risk of CVD later in life. Early identification of such women in the peri- and postpartum period and active follow-up by a general internist or referral to a Specialty Vascular Risk Reduction clinic 
(if available) can help to connect women with the resources and support needed for lifestyle interventions and medical treatment if appropriate. Work remains to be done in defining thresholds for starting potentially lifelong medications in these young women, as well as optimal targets for treatment.

We hope to make physicians aware that older women should also be screened for a history of maternal placental syndromes and pregnancy complications, as these factors have not typically been included outside of the obstetrics and gynecology setting when teaching trainees to take a past medical history. Validated education tools exist ${ }^{5}$ and practitioners can share these tools with both patients and colleagues to increase awareness.

Finally, this case highlights the need for knowledge translation of pre-eclampsia as a long-term vascular risk factor into lipid guidelines for arguably secondary prevention in this often under-recognized population.

\section{Declarations}

The authors declare this case report to be original work, and do not have any commercial interests in this subject.

\section{References}

1. Mosca L, Benjamin EJ, Berra K et al. Effectiveness-based guidelines for the prevention of cardiovascular disease in women--2011 update: a guideline from the American Heart Association. Circulation 2011;123(11):1243-62.
2. Anderson TJ, Grégoire J, Pearson G et al. 2016 Canadian Cardiovascular Society guidelines for the management of dyslipidemia for the prevention of cardiovascular disease in the adult. Can J Cardiol 2016;32:1263-82.

3. Janmohamed R, Montgomery-Fajic E, Sia W et al. Cardiovascular risk reduction and weight management at a hospital-based postpartum preeclampsia clinic. J Obstet Gynaecol Can 2015;37(4):330-7.

4. Magee LA, Pels A, Helewa M et al. Diagnosis, evaluation, and management of the hypertensive disorders of pregnancy: executive summary. J Obstet Gynaecol Can 2014;36(5):416-41.

5. Pre-eclampsia Foundation. Heart Disease and Stroke. [Internet]. Available at: http://www.preeclampsia.org, http://www.preeclampsia.org/healthinformation/heart-disease-stroke and http://www.preeclampsia.org/ care-providers.

6. 6. Fraser A, Nelson SM, Macdonald-Wallis C et al. Associations of pregnancy complications with calculated cardiovascular disease risk and cardiovascular risk factors in middle age- The Avon Longitudinal Study of Parents and Children. Circulation 2012;125(11):1367-80.

7. Bellamy L, Casas JP, Hingorani AD, Williams DJ. Pre-eclampsia and risk of cardiovascular disease and cancer in later life: systematic review and metaanalysis. BMJ 2007;335(7627):974.

8. Brown MC, Best KE, Pearce MS, et al. Cardiovascular disease risk in women with pre-eclampsia: Systematic review and meta-analysis. Eur J Epidemiol 2013;28:1-19.

9. Ray JG, Vermeulen MJ, Schull MJ, Redelmeier DA. Cardiovascular health after maternal placental syndromes (CHAMPS): population-based retrospective cohort study. Lancet 2005;366(9499):1797-803.

10. Stone NJ, Robinson JG, Lichtenstein AH et al. 2013 ACC/AHA guideline on the treatment of blood cholesterol to reduce atherosclerotic cardiovascular risk in adults: a report of the American College of Cardiology/American Heart Association Task Force on Practice Guidelines. Circulation 2014;129(25, suppl 2):S1-S45. 